\title{
Metabolic Syndrome Is Associated with Increased Breast Cancer Risk: A Systematic Review with Meta-Analysis
}

\author{
Ruchi Bhandari, ${ }^{1}$ George A. Kelley, ${ }^{2}$ Tara A. Hartley, ${ }^{3}$ and Ian R. H. Rockett ${ }^{1}$ \\ ${ }^{1}$ Department of Epidemiology, School of Public Health, West Virginia University, Morgantown, WV 26506, USA \\ ${ }^{2}$ Department of Biostatistics, School of Public Health, West Virginia University, Morgantown, WV 26506, USA \\ ${ }^{3}$ National Institute for Occupational Safety and Health, Centers for Disease Control and Prevention, Atlanta, GA 30333, USA \\ Correspondence should be addressed to Ruchi Bhandari; bhandariruchi@yahoo.com
}

Received 16 June 2014; Revised 24 November 2014; Accepted 26 November 2014; Published 29 December 2014

Academic Editor: Zsuzsanna Kahà̀

Copyright (C) 2014 Ruchi Bhandari et al. This is an open access article distributed under the Creative Commons Attribution License, which permits unrestricted use, distribution, and reproduction in any medium, provided the original work is properly cited.

\begin{abstract}
Background. Although individual metabolic risk factors are reported to be associated with breast cancer risk, controversy surrounds risk of breast cancer from metabolic syndrome (MS). We report the first systematic review and meta-analysis of the association between MS and breast cancer risk in all adult females. Methods. Studies were retrieved by searching four electronic reference databases [PubMed, Cumulative Index to Nursing and Allied Health Literature (CINAHL), Web of Science, and ProQuest through June 30, 2012] and cross-referencing retrieved articles. Eligible for inclusion were longitudinal studies reporting associations between MS and breast cancer risk among females aged 18 years and older. Relative risks and 95\% confidence intervals were calculated for each study and pooled using random-effects models. Publication bias was assessed quantitatively (Trim and Fill) and qualitatively (funnel plots). Heterogeneity was examined using $Q$ and $I^{2}$ statistics. Results. Representing nine independent cohorts and 97,277 adult females, eight studies met the inclusion criteria. A modest, positive association was observed between MS and breast cancer risk (RR: $1.47,95 \% \mathrm{CI}, 1.15-1.87 ; z=3.13 ; p=0.002 ; Q=26.28, p=0.001 ; I^{2}=69.55 \%$ ). No publication bias was observed. Conclusions. MS is associated with increased breast cancer risk in adult women.
\end{abstract}

\section{Introduction}

Breast cancer, the most common cancer in women worldwide, accounted for 1.7 million new cases in 2012, comprising a quarter of all new cancer cases [1]. While traditional risk factors for breast cancer include age, family history of cancer, and reproductive and menstrual history, the National Cancer Institute also recognizes overweight, lack of physical activity, and consumption of alcohol as risk factors [2]. Several of these risk factors are associated with metabolic syndrome [3].

Metabolic syndrome (MS) is a cluster of pathophysiological disorders comprising central obesity, insulin resistance, high blood pressure, and dyslipidemia. Reaven's definition of MS in 1988 [4] was followed by definitions from the World Health Organization [5], National Cholesterol Education Program's Adult Treatment Panel III (NCEP ATP III) [6], American Heart Association/National Heart, Lung, and Blood Institute [7], and the International Diabetes Federation
[8]. The NCEP ATP III guidelines are the most commonly used criteria in the US [6]. These criteria include the presence of three or more of the following [3]: abdominal obesity (waist circumference $\geq 35$ inches in women), triglycerides $\geq$ $150 \mathrm{mg} / \mathrm{dL}$, high density lipoprotein cholesterol (HDL-C) < $50 \mathrm{mg} / \mathrm{dL}$, blood pressure (BP) $\geq 130 / 85 \mathrm{mmHg}$, and fasting glucose $\geq 110 \mathrm{mg} / \mathrm{dL}$. MS is estimated to be prevalent in at least a quarter of the adults in the Americas, in Europe, and in India [9].

MS has been identified as a risk factor for several cancers, particularly breast, pancreatic, colorectal, and prostate cancers [10-15]. Individual components of MS, for example, abdominal obesity, high blood glucose, high BP, high triglycerides, and low HDL, are positively associated with the development of certain cancers, most notably breast cancer [16-27]. While studies show a positive association of breast cancer with diabetes $[19,28-33]$ and obesity [16, $34,35]$, others show a negative association with obesity in 
premenopausal women [36-38]. Mixed results also characterize hypertension $[22,23,39,40]$ and dyslipidemia $[22,41$, 42] as risk factors for breast cancer. In addition, although individual components of MS may not be strongly associated with the development of breast cancer, their combination may elevate the risk [13, 14, 43-56]. For example, MS may activate different molecular pathways through endocrine, metabolic, and immune cell changes, which in turn influence breast tumorigenesis [47]. Such pathways that enhance breast cancer cell proliferation and inhibit apoptosis include (1) increased levels of circulating estrogen, for example, estradiol $[52,54,57],(2)$ higher levels of insulin $[58,59],(3)$ decreased level of circulating adiponectin [60], (4) increased plasma leptin concentration [60], and (5) increased production of proinflammatory cytokines, such as interleukin- 6 and tumor necrosis factor alpha [61].

Previous epidemiologic studies on MS and breast cancer risk show contrary results. For example, only four $[13,14$, $43,51]$ of eight studies [13, 14, 43, 48, 51, 62-64] reported a statistically significant association between MS and risk of breast cancer. This might invite a conclusion that the association between MS and breast cancer risk is unknown. However, such an inference would be based on the votecounting approach, an approach that ignores the magnitude of the association [65].

A recent systematic review and meta-analysis of MS and postmenopausal breast cancer found that MS was moderately associated with the risk of postmenopausal breast cancer [10]. However, to the best of our knowledge, no metaanalytic research has addressed the conflicting results from individual studies of MS and breast cancer risk in all adult women. Therefore, the purpose of this study was to use the aggregate data meta-analytic approach to examine the association between MS and breast cancer risk in women.

\section{Methods}

2.1. Study Eligibility. The a priori inclusion criteria for this study were as follows: (1) observational studies using cohort (both prospective and retrospective), case-control, or nested case-control study designs; (2) studies examining the association between MS (presence of a cluster of three or more metabolic abnormalities) and breast cancer incidence, as defined by the authors; (3) studies with adult females $\geq 18$ years of age as participants; (4) English-language studies published as journal articles, doctoral dissertations, or masters' theses; (5) published and indexed studies up to June 30, 2012; and (6) studies reporting sufficient data (e.g., rate ratios, risk ratios, odds ratios, standardized incidence ratios, hazard ratios, or frequencies) for calculating a common effect size. Neither lobular carcinoma in situ nor ductal carcinoma in situ breast cancer cases were excluded from the study.

Studies not meeting all inclusion criteria were excluded from this review. Excluded studies were those that (1) were not published as full reports, such as conference abstracts and letters to the editors; (2) only examined individual components of MS; (3) measured the MS variables at time of cancer diagnosis; (4) used cancer mortality, rather than incidence, as the outcome; and (5) were published in a language other than English.

2.2. Data Sources. A comprehensive and systematic search was conducted using four electronic databases: PubMed, Cumulative Index to Nursing and Allied Health Literature (CINAHL), Web of Science, and ProQuest (from their commencement to June 30, 2012). Since the term MS dates back to the late 1950s, with variations in use as early as the 1920s, the start dates of each of the databases were used as the commencement date for study search: Web of Science (1900), CINAHL (1952), PubMed (1966), and ProQuest (1861). In addition, cross-referencing from retrieved studies was also performed. Major keywords used in the search for potentially eligible studies included "metabolic syndrome" ("insulin resistance syndrome," "syndrome $\mathrm{x}$ ") and "breast cancer" ("neoplasm and breast"). Using the most recent publication, trials published as duplicate reports (parallel publications) were only included once. All electronic searches were conducted using the graphical user interface for each database. The last search was conducted on June 30, 2012. An initial cut-off point for the inclusion of studies was not used given the difficulty in establishing such a point, as well as our concern about the potential loss of studies that met our eligibility criteria.

2.3. Study Selection. At the first screening, one author (RB) screened all abstracts and selected articles for full-text examination. At the second level of the study selection process, two of the authors ( $\mathrm{RB}$ and $\mathrm{TH}$ ) examined the full-text articles and then selected the included studies following mutual discussion and consensus.

2.4. Data Extraction. Two of the authors (RB and $\mathrm{TH}$ ) reviewed every study selected and independently extracted data from studies onto electronic coding forms. These forms could hold up to 52 items per study. Attempts were made to contact authors of three of the original studies for missing information $[13,62,64]$, but only one provided the requested information [13]. After initial coding, the two coders (RB and $\mathrm{TH}$ ) reviewed each item for agreement. Discrepancies were resolved by consensus. Using Cohen's kappa $(k)$ statistic [66], the overall interrater agreement rate prior to correcting discrepant items was 0.96 for all included studies.

2.5. Risk of Bias Assessment. Risk of bias was assessed using a modified version of Strengthening the Reporting of Observational Studies in Epidemiology (STROBE) checklist [67]. The items assessed included (1) study design, (2) adjustments for confounders, (3) selection of participants and their eligibility criteria, (4) measurement of predictor variables, (5) breast cancer diagnosis, (6) study size, (7) handling of missing data, and (8) reasons for nonparticipation of individuals at each stage of the study. A description of the criteria for risk of bias assessment is shown in Table 1. Two of the authors (RB and $\mathrm{TH}$ ) conducted all assessments, independently of each other. Disagreements were resolved through discussion. No 
TABLE 1: Criteria for risk of bias assessment.

\begin{tabular}{|c|c|c|c|}
\hline Criteria & Low risk & High risk & Unclear risk \\
\hline Study design & $\begin{array}{l}\text { Prospective or retrospective cohort, } \\
\text { nested case-control }\end{array}$ & Case-control & $\begin{array}{l}\text { Information not } \\
\text { reported }\end{array}$ \\
\hline Adjustment of confounders & $\begin{array}{l}\text { Adjusted for } 4 \text { or more of the following: } \\
\text { age, education/income, family history of } \\
\text { cancer, hormone therapy use/oral } \\
\text { contraceptive use/reproductive history, } \\
\text { smoking status, and alcohol consumption }\end{array}$ & $\begin{array}{l}\text { Adjusted for } 3 \text { or less of the following: } \\
\text { age, education/income, family history } \\
\text { of cancer, hormone therapy use/oral } \\
\text { contraceptive use/reproductive history, } \\
\text { smoking status, and alcohol } \\
\text { consumption }\end{array}$ & $\begin{array}{l}\text { Information not } \\
\text { reported }\end{array}$ \\
\hline $\begin{array}{l}\text { Selection of participants } \\
\text { and their eligibility criteria }\end{array}$ & $\begin{array}{l}\text { Studies clearly stating their eligibility } \\
\text { criteria and the sources and methods of } \\
\text { selection of participants }\end{array}$ & $\begin{array}{l}\text { Studies not clearly stating their } \\
\text { eligibility criteria and the sources and } \\
\text { methods of selection of participants }\end{array}$ & $\begin{array}{l}\text { Information not } \\
\text { reported }\end{array}$ \\
\hline $\begin{array}{l}\text { Measurement of predictor } \\
\text { variables }\end{array}$ & Identified through objective measures & $\begin{array}{l}\text { Self-reported or pharmaceutical } \\
\text { prescriptions }\end{array}$ & $\begin{array}{l}\text { Information not } \\
\text { reported }\end{array}$ \\
\hline Breast cancer diagnosis & $\begin{array}{l}\text { Histologically confirmed or identified } \\
\text { through cancer registry/medical records }\end{array}$ & Self-reported & $\begin{array}{l}\text { Information not } \\
\text { reported }\end{array}$ \\
\hline Study size & Large enough for adequate power & Not large enough for adequate power & $\begin{array}{l}\text { Information not } \\
\text { reported }\end{array}$ \\
\hline Handling of missing data & Missing data analysis specified & Missing data deleted from analysis & $\begin{array}{l}\text { Information not } \\
\text { reported }\end{array}$ \\
\hline $\begin{array}{l}\text { Reasons for } \\
\text { nonparticipation of } \\
\text { individuals at each stage of } \\
\text { the study }\end{array}$ & $\begin{array}{l}\text { Reasons clearly reported for each stage of } \\
\text { study }\end{array}$ & $\begin{array}{l}\text { Reasons not reported for each stage of } \\
\text { study }\end{array}$ & $\begin{array}{l}\text { Information not } \\
\text { reported }\end{array}$ \\
\hline
\end{tabular}

study was excluded based on the results of the risk of bias assessment.

\subsection{Statistical Analysis}

2.6.1. Calculation of Study-Level Effect Sizes. Risk estimates were used to examine the association between MS and risk of breast cancer. These were derived from reported relative risks, odds ratios, hazard ratios, incident rate ratios, or standardized incidence ratios, together with corresponding 95\% confidence intervals (CIs), from the original studies. Where necessary and possible, all metrics were converted to risk ratios (RRs). Adjusted risk estimates were pooled for analysis from multivariable models in the original studies. However, for two case-control studies that were included $[14,51]$, adjusted odds ratios were used because of the lack of the requisite data to convert odds ratios to RRs.

2.6.2. Effect Size Pooling. All RR results were pooled using a random-effects model, an approach that incorporates between-study heterogeneity into the model [68]. A $z$-score two-tailed alpha value $\leq 0.05$ was considered to be statistically significant. In addition, 95\% CIs were calculated for each result from each study as well as for pooled estimates. Heterogeneity was calculated using the Q [69] and $I^{2}$ statistics [70]. An alpha level $\leq 0.10$ for the $Q$ statistic was considered to be evidence of statistically significant heterogeneity. While somewhat arbitrary, $I^{2}$ values of $25 \%, 50 \%$, and $75 \%$ were considered to represent low, moderate, and high amounts of heterogeneity [70]. Publication bias was assessed using the Trim and Fill approach of Duval and Tweedie [71]. In addition, Rosenthal's Fail-Safe $N$ test was used to compute the number of missing null studies that would be needed to nullify the overall pooled RR as being statistically significant [72]. Statistically significant standardized residuals $(p \leq 0.05)$ were considered to be outliers.

2.6.3. Sensitivity Analyses. Influence analysis was conducted with each study result deleted from the model once, in order to examine the effects of each on the overall pooled results. Cumulative meta-analysis, ranked by year, was also conducted in order to examine the accumulation of results over time. A separate pooled analysis, limited to postmenopausal women, was conducted because studies show that MS in postmenopausal women increases the risk of breast cancer $[13,14,43,48,51,62]$. In addition, pooled analyses were conducted with the following caveats post hoc: (1) deletion of results from two case-control studies because odds ratios were used instead of $\operatorname{RR}[14,51]$, (2) deletion of results from studies that were not prospective cohort designs $[13,14,51]$, and (3) limiting the results to studies that controlled for four or more of the important confounders (as listed in Table 1) $[14,43,48,51]$. Given the potential for diabetes and diabetes medications to affect breast cancer risk, post hoc data analysis was also conducted with studies that included participants with diabetes and/or taking medications for diabetes, deleted from the model $[14,43,64]$. All analyses were performed using Comprehensive Meta-Analysis, Version 2.2 [73].

\section{Results}

3.1. Study Characteristics. Figure 1 presents a flow diagram of the selection of studies for the meta-analysis. Of the 291 


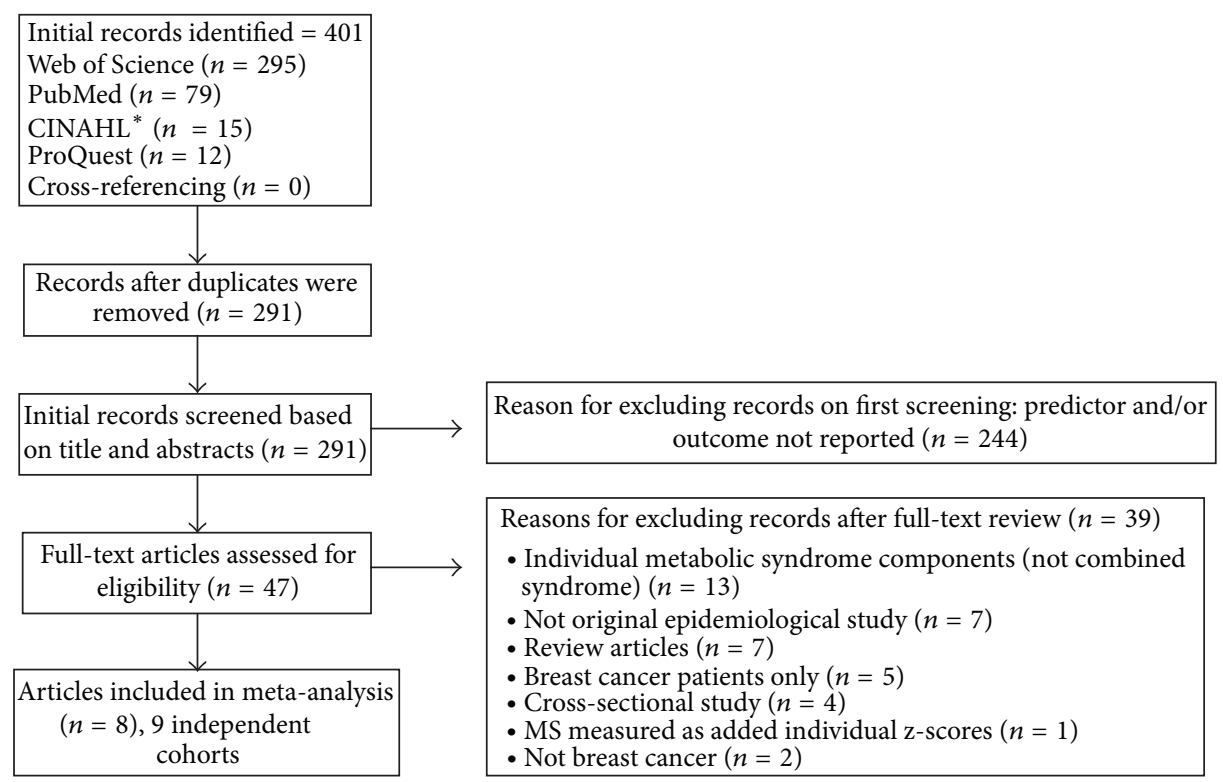

Figure 1: Flow diagram describing the selection of studies. * CINAHL: Cumulative Index to Nursing and Allied Health Literature.

studies screened, 47 (16.2\%) were selected for full-text review: 25 from PubMed [14, 43-55, 64, 74-83], 17 from the Web of Science [13, 39, 63, 84-97], one from CINAHL [98], and four from ProQuest [62, 99-101]. Eight (17.0\%) of the 47 studies that underwent a full-text review met the eligibility criteria $[13,14,43,48,51,62-64]$. One article [14] presented results for two independent cohorts; thus each cohort was treated independently.

A general description of the included studies is shown in Table 2. Studies were published between 2008 and 2012 and from five different countries. The study designs included four prospective cohorts [48, 62-64], one retrospective cohort [13], one prospective nested case-control study [43], and two case-control studies [14, 51]. The baseline year for cohort inception ranged from 1983 to 2004, with average followup ranging between 2.7 and 13.5 years. Sample sizes ranged from 792 to 49,172 (total 97,277) adult females, excluding one study that did not report these data [64]. The ages of the participants ranged from 21 to 86 years. Six studies conducted analyses on postmenopausal women [13, 14, 43, $48,51,62]$. The results of each cohort or case-control study were initially reported as a hazard ratio $[13,48,63]$, incidence rate ratio $[43,62]$, standardized incidence ratio [64], or odds ratio [14, 51]. Methods for exposure assessment, cancer identification, and control of confounders varied across the eight included studies (Table 3). Seven studies identified the outcome (breast cancer) through histological reports or medical reports or from a cancer registry $[13,14,43,48,51$, $62,64]$, while one used self-report [63]. Only three studies examined invasive breast cancer cases $[43,48,64]$. One study also reported on the in situ breast cancer cases but there were only seven such cases in that study [43]. Another study analyzed all breast cancer cases (in situ and invasive) as well as invasive cancers separately, and results remained unchanged [48].
3.2. Risk of Bias Assessment. Risk of bias results are shown in Table 4. All of the studies were considered to be at low risk for selection of participants and meeting eligibility criteria in addition to providing adequately powered sample sizes. Out of eight studies, a majority were also considered low risk with respect to study design (six studies) and measurement of the outcome variable (seven studies). In terms of handling potential confounders, half the studies were low risk, three were high risk, and one was unclear risk. Missing confounding variables included education, smoking status, alcohol use, family history of cancer, contraceptive use, or hormonal history. Similarly, half the studies had objective measurements of predictor variables, while the remainder relied on self-report, and were consequently considered high risk. Four studies deleted the participants with missing variables in their analyses (high risk), while two did not report how they handled missing data. Lastly, six studies were considered high risk because they did not report the reasons for nonparticipation of subjects at each stage of follow-up.

\subsection{Statistical Analysis}

3.3.1. Overall Results. Overall, a statistically significant increase of $47 \%$ in the risk for incident breast cancer was observed for adult females with MS (RR: 1.47, 95\% CI, 1.151.87; $z=3.13 ; p<0.002 ; Q=26.28, p<0.001$; $I^{2}=69.55 \%$ ) (Figure 2 ). With the exception of one study [63], all other studies had RR in the direction of increased risk $[13,14,43,48,51,62,64]$. Funnel plot results for potential publication bias are shown in Figure 3. Using the Trim and Fill approach that resulted in two imputations, the risk decreased by $16 \%$ but remained significant (RR: 1.31, 95\% CI, 1.01-1.70). The Fail-Safe $\mathrm{N}$ was 69 , implying that 69 "null" studies would be needed to nullify the statistically 


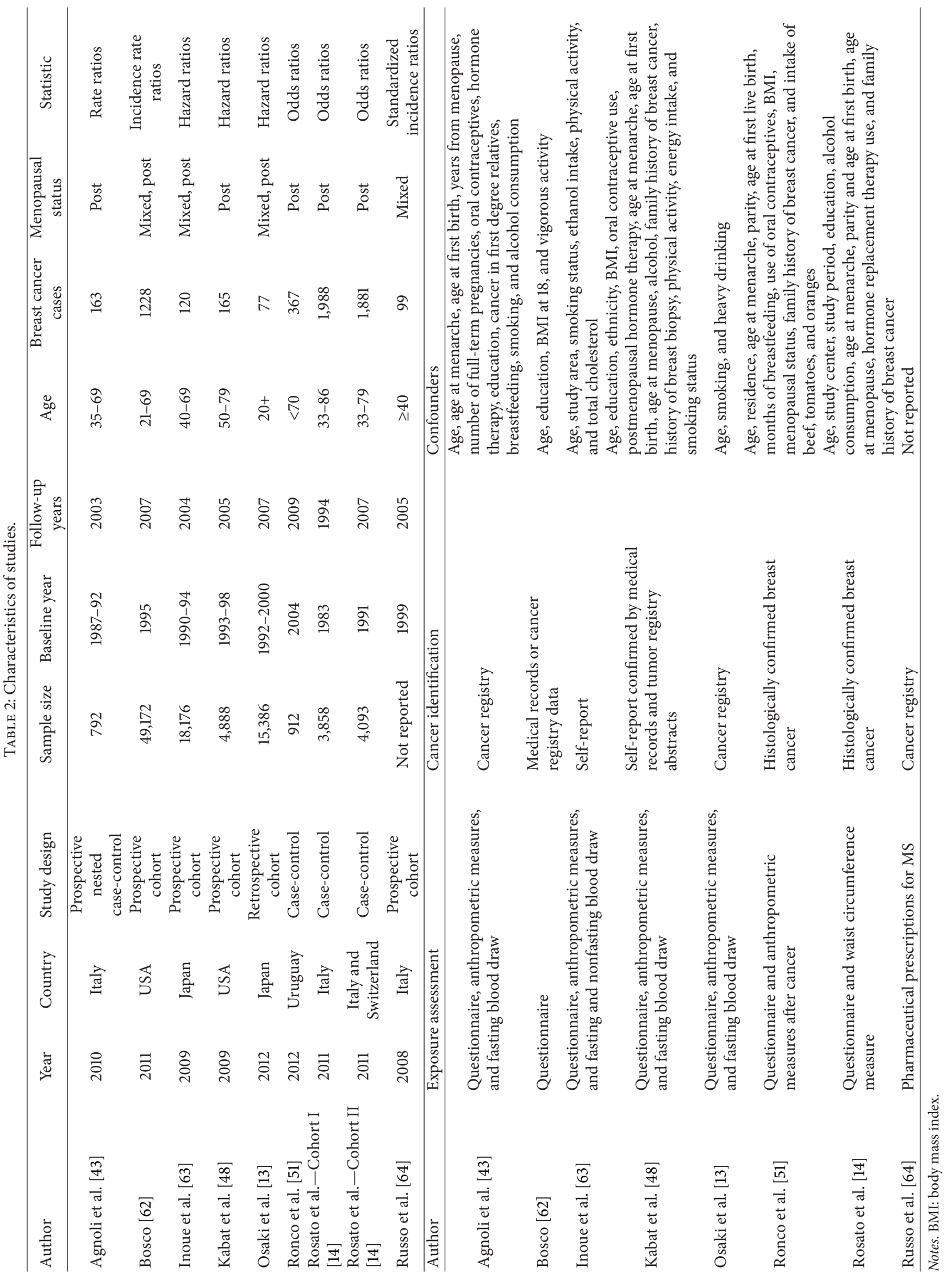


TABLE 3: Definitions and criteria for metabolic syndrome in the included studies.

2 definitions ( $\geq 3$ of the following components).

(1) The highest or lowest (HDL-C) tertiles in controls: WC $>86 \mathrm{~cm}$; triglycerides $>126 \mathrm{mg} / \mathrm{dL}$; HDL-C $\leq=$

Agnoli et al. [43]

$55 \mathrm{mg} / \mathrm{dL}$; fasting glucose $>88 \mathrm{mg} / \mathrm{dL}$ (or previously diagnosed Type 2 Diabetes Mellitus); mean BP $\geq$

$106.5 \mathrm{mmHg}$ (or treatment for previously diagnosed HTN).

(2) NCEP: WC $>88 \mathrm{~cm}$; triglycerides $\geq 150 \mathrm{mg} / \mathrm{dL}$; HDL-C $<50 \mathrm{mg} / \mathrm{dL}$; $\mathrm{SBP} \geq 130 \mathrm{mmHg}$ or diastolic $\mathrm{BP} \geq$ $85 \mathrm{mmHg}$; fasting glucose $\geq 110 \mathrm{mg} / \mathrm{dL}$.

Bosco [62]

$\geq 3$ of the following components: WC $\geq 88 \mathrm{~cm}$; Type 2 Diabetes Mellitus self-reported diagnosis at $\geq 30$ years at baseline; HTN self-reported diagnosis plus diuretics or hypertensive medication use at baseline; cholesterol self-reported diagnosis of high cholesterol and cholesterol-lowering medication at baseline.

2 definitions.

Inoue et al. [63]

(1) Grundy (NHLBI 2005): any 3 or more: BMI $\geq 25 \mathrm{~kg} / \mathrm{m}^{2} ; \mathrm{HTN} \geq 130 / 85 \mathrm{mmHg}$ or medication use; glucose $\geq$ $100 \mathrm{mg} / \mathrm{dL}$ fasting or $140 \mathrm{mg} / \mathrm{dL}$ nonfasting or on treatment; low HDL-C $<50 \mathrm{mg} / \mathrm{dL}$; triglycerides $\geq 150 \mathrm{mg} / \mathrm{dL}$. (2) IDF: overweight and at least 2 other components.

Kabat et al. [48] ATP III modified to exclude those with glucose $\geq 126 \mathrm{mg} / \mathrm{dL}$ or those taking diabetic medication.

Osaki et al. [13] 6 definitions: Japan 2005, modified NCEP 2001, modified NCEP 2004, modified IDF 2006, modified WHO 1999, and NCEP 2001 with BP 140/90.

2 definitions.

Ronco et al. [51] (1) Diabetes + overweight + HTN.

(2) Diabetes + overweight + dyslipidemia.

Rosato et al. [14]

Russo et al. [64]

Combined presence of diabetes, drug-treated HTN, drug-treated hyperlipidemia (as a proxy indicator of elevated triglycerides and reduced HDL-C), and WC $\geq 88 \mathrm{~cm}$ or BMI $\geq 30 \mathrm{~kg} / \mathrm{m}^{2}$ when WC was missing. Pharmacological definition: patients who chronically received antihypertensive, glucose-lowering, and lipid modifying drugs.

Notes. BMI: body mass index; BP: blood pressure; HDL-C: high density lipoprotein cholesterol; HTN: hypertension; WC: waist circumference; IDF: International Diabetes Federation; NCEP ATP III: National Cholesterol Education Program's Adult Treatment Panel III; NHLBI: National Heart, Lung, and Blood Institute; WHO: World Health Organization.

TABLE 4: Study-level results for risk of bias assessment.

\begin{tabular}{|c|c|c|c|c|c|c|c|c|}
\hline & $\begin{array}{c}\text { Agnoli et } \\
\text { al. [43] }\end{array}$ & Bosco $[62]$ & $\begin{array}{c}\text { Inoue et al. } \\
{[63]}\end{array}$ & $\begin{array}{c}\text { Kabat et al. } \\
{[48]}\end{array}$ & $\begin{array}{c}\text { Osaki et al. } \\
\text { [13] }\end{array}$ & $\begin{array}{c}\text { Ronco et } \\
\text { al. [51] }\end{array}$ & $\begin{array}{l}\text { Rosato et } \\
\text { al. [14] }\end{array}$ & $\begin{array}{l}\text { Russo et } \\
\text { al. [64] }\end{array}$ \\
\hline \multicolumn{9}{|l|}{ Methods } \\
\hline Study design & Low & Low & Low & Low & Low & High & High & Low \\
\hline Variables (confounders) & Low & High & High & Low & High & Low & Low & Unclear \\
\hline Participants (eligibility, selection) & Low & Low & Low & Low & Low & Low & Low & Low \\
\hline Data sources/predictor measurement & Low & High & Low & Low & Low & High & High & High \\
\hline Data sources/outcome measurement & Low & Low & High & Low & Low & Low & Low & Low \\
\hline Study size (adequate power) & Low & Low & Low & Low & Low & Low & Low & Low \\
\hline Missing data analysis & High & High & High & Low & High & Low & Unclear & Unclear \\
\hline \multicolumn{9}{|l|}{ Results } \\
\hline Participants (non-participation) & High & High & High & High & Low & Low & High & High \\
\hline
\end{tabular}

significant association between MS and breast cancer risk in adult females. No statistically significant outliers were identified $(p=0.06-0.82)$.

3.3.2. Sensitivity Analyses. With each study deleted from the model once, results remained positive and statistically significant (Figure 4). The pooled RR fell within a range of $20 \%(\mathrm{RR}=1.36-1.56)$ and none of the CIs for the point estimates was less than 1.0. Cumulative meta-analysis, ranked by year, revealed that results have been statistically significant since 2011 (Figure 5). Deleting the two case-control studies from the model, the RR for incident breast cancer for women with MS decreased by $18 \%$ but was still statistically significant with moderate heterogeneity (RR: 1.29, 95\% CI, 1.003-1.67; $\left.z=1.98 ; p=0.05 ; Q=14.13, p=0.01 ; I^{2}=64.61 \%\right)$. When limited to studies with only prospective designs, the RR decreased by $30 \%$ but remained statistically significant with very low heterogeneity (RR: $1.17,95 \% \mathrm{CI}, 1.01-1.36 ; z=2.04$; $\left.p=0.04 ; Q=4.30, p=0.37 ; I^{2}=7.04 \%\right)$. When limited to postmenopausal women, breast cancer risk increased by $34 \%$ and was still statistically significant with high heterogeneity (RR: 1.81, 95\% CI, 1.28-2.56; $z=3.37 ; p=0.001 ; Q=23.36$, $\left.p=0.001 ; I^{2}=74.32 \%\right)$. When limiting the results to studies that controlled for four or more of the important confounders (as listed in Table 1) [14, 43, 48, 51], breast cancer risk increased by $17 \%$ and was statistically significant with moderate heterogeneity (RR: 1.64, 95\% CI, 1.23-2.20; $z=3.34$; $\left.p=0.001 ; Q=8.55, p=0.07 ; I^{2}=53.21 \%\right)$. Lastly, 


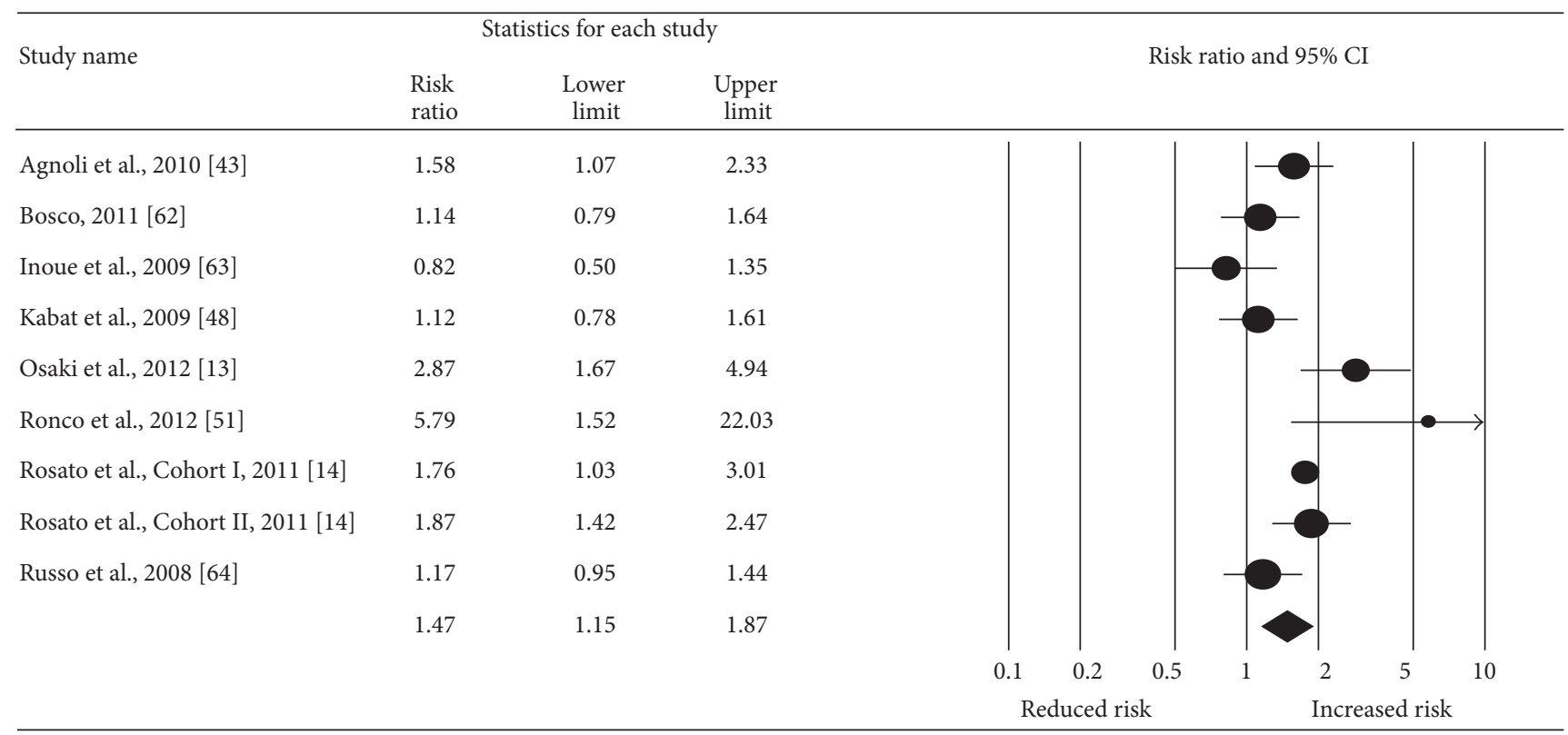

FIGURE 2: Forest plot for metabolic syndrome and breast cancer risk (random-effects model). The black circles represent the weighted risk ratio (RR) for each result from each study, while the horizontal lines represent the lower and upper 95\% confidence intervals (CI) for the RR. The black diamond represents the overall pooled RR, while the left and right sides of the diamond represent the lower and upper 95\% CI for the pooled RR. For studies that included more than one definition of metabolic syndrome, the following were used: Agnoli et al. (tertile definition), Bosco (time-independent definition), Osaki et al. (modified NCEP 2001 definition), and Ronco et al. (diabetes, overweight, and hypertension definition).

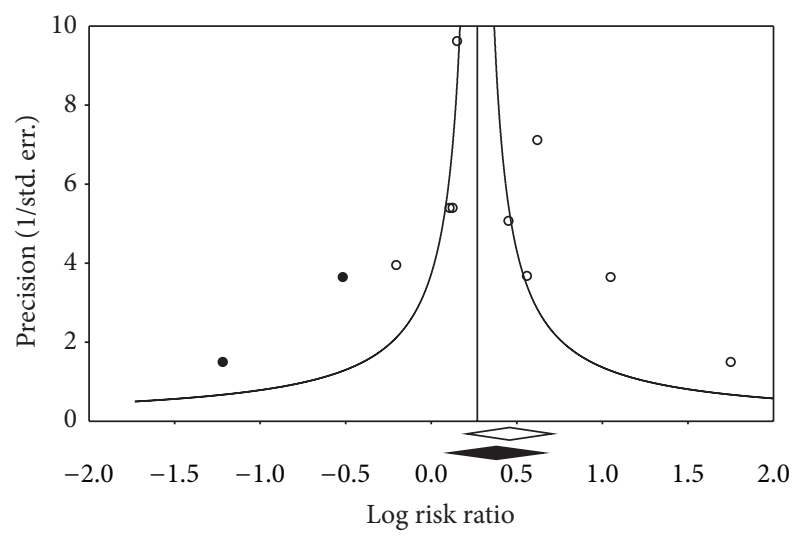

FIGURE 3: Funnel plot of precision by log risk ratio.

when data were analyzed after deleting from the model those studies that had participants with diabetes or taking medications for diabetes $[14,43,64]$, the RR was slightly larger than the overall finding but the 95\% CI included 1.0 (RR: $1.48,95 \%$ CI, $0.92-2.4 ; z=1.61 ; p=0.11 ; Q=17.4$, $\left.p=0.02 ; I^{2}=76.96 \%\right)$.

\section{Discussion}

The purpose of this aggregate data meta-analysis was to examine the association between MS and the risk for breast cancer in adult females. Overall, the results suggest that there was a modest positive association between MS and risk of breast cancer. This finding is strengthened by the robustness of results from other analyses. These include (1) examination for publication bias, (2) influence analysis with each study being deleted from the model once, (3) deletion of the two case-control studies with odds ratios from the overall model, (4) limiting the analysis to prospective designs, (5) including only postmenopausal women in the analysis, and (6) limiting the results to studies that controlled for four or more of the important confounders. In addition, the results from cumulative meta-analysis, ranked by year, indicate an increasingly statistically significant association since 2011. In contrast, despite a slightly increased mean RR, overlapping CIs were observed when studies that included participants with diabetes or taking medications for diabetes were deleted from the model $[14,43,64]$. However, whether this reduced precision is the result of these specific characteristics or some other factors, for example, loss of power with a reduced number of studies, is not known.

Assessment for risk of bias indicated that a majority of studies were at low risk regarding study design, cancer assessment, and sample size. However, a majority were at high risk or unclear risk in terms of handling of missing data and nonparticipation of subjects at each stage of follow-up. It is suggested that future studies provide complete information on the handling of missing data and on the nonparticipation of subjects at each stage of follow-up.

When limited to postmenopausal women, a stronger association between MS and breast cancer was observed. This association was stronger in case-control and retrospective cohort study designs compared to prospective cohort study 


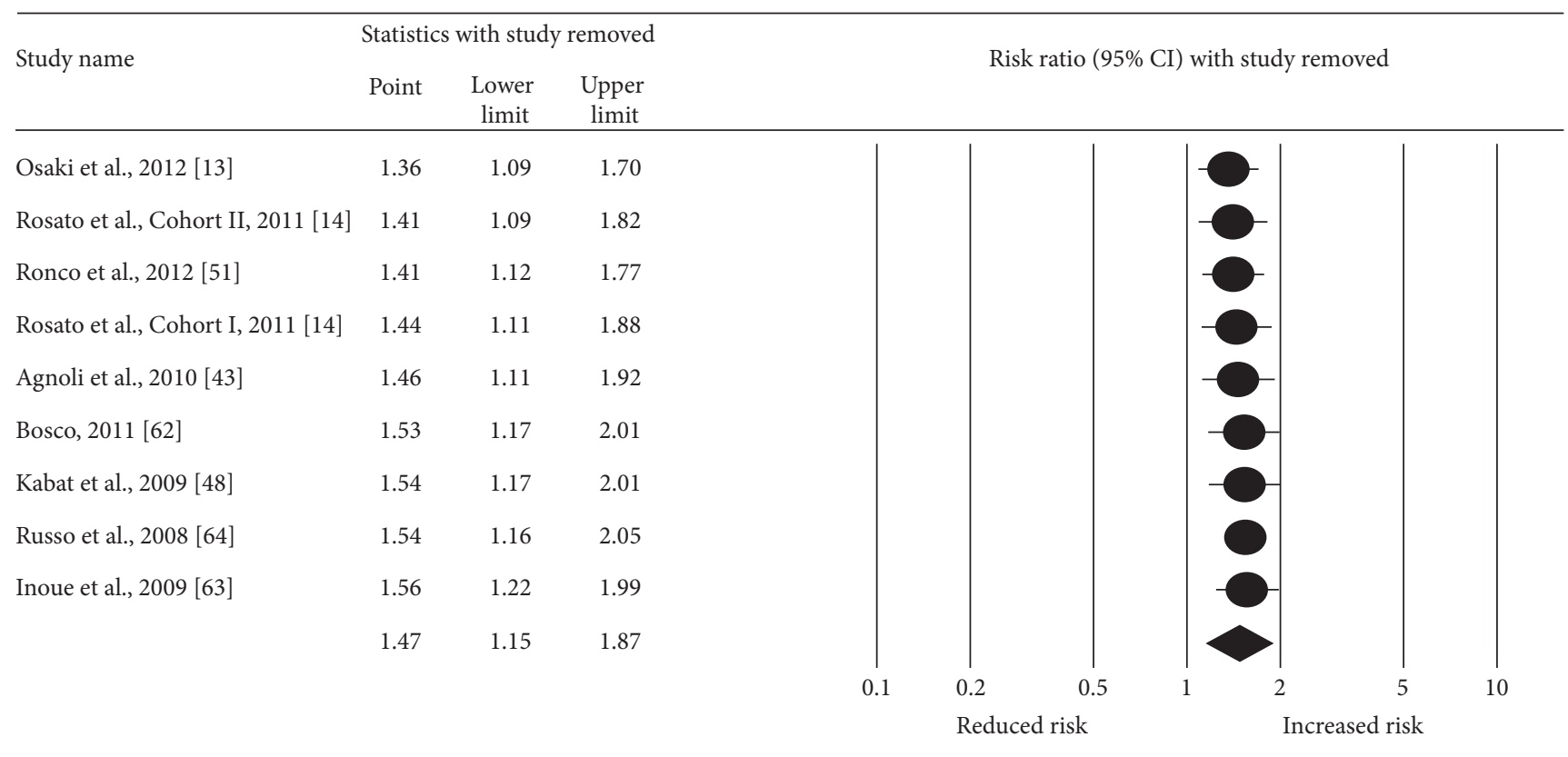

FIGURE 4: Influence analysis with each result from each study deleted from the random-effects model once. The black circles represent the risk ratio (RR) for each result from each study while the horizontal lines represent the lower and upper 95\% confidence interval (CI) for the RR. The black diamond represents the overall pooled result while the left and right sides of the diamond represent the lower and upper $95 \%$ CI for the pooled RR. For studies that included more than one definition of metabolic syndrome, the following were used: Agnoli et al. (tertile definition), Bosco (time-independent definition), Osaki et al. (modified NCEP 2001 definition), and Ronco et al. (diabetes, overweight, and hypertension definition).

\begin{tabular}{lcccc}
\hline \multirow{2}{*}{ Study name } & $\begin{array}{c}\text { Cumulative statistics } \\
\text { Point }\end{array}$ & $\begin{array}{c}\text { Lower } \\
\text { limit }\end{array}$ & $\begin{array}{c}\text { Upper } \\
\text { limit }\end{array}$ \\
\hline Russo et al., 2008 [64] & 1.17 & 0.95 & 1.44 \\
Inoue et al., 2009 [63] & 1.06 & 0.77 & 1.45 \\
Kabat et al., 2009 [48] & 1.11 & 0.94 & 1.32 \\
Agnoli et al., 2010 [43] & 1.17 & 0.96 & 1.44 \\
Bosco, 2011 [62] & 1.17 & 1.01 & 1.36 \\
Rosato et al., Cohort I, 2011 [14] & 1.21 & 1.03 & 1.43 \\
Rosato et al., Cohort II, 2011 [14] & 1.31 & 1.07 & 1.61 \\
Osaki et al., 2012 [13] & 1.41 & 1.12 & 1.77 \\
Russo et al., 2008 [51] & 1.47 & 1.15 & 1.87 \\
\hline
\end{tabular}

FiguRE 5: Cumulative meta-analysis, ranked by year and based on a random-effects model. The black circles represent the cumulative risk ratios (RR) while the horizontal lines represent the lower and upper 95\% confidence intervals (CI) for the RR. The black diamond represents the overall pooled RR while the left and right sides of the diamond represent the lower and upper 95\% CI for the pooled RR. For those studies that included more than one definition of metabolic syndrome, the following were used: Agnoli et al. (tertile definition), Bosco (timeindependent definition), Osaki et al. (modified NCEP 2001 definition), and Ronco et al. (diabetes, overweight, and hypertension definition). 
designs. These findings concur with those from a recent meta-analysis on MS and breast cancer risk in postmenopausal women [10]. Several studies have shown that MS in this group increases the risk of breast cancer [43, 46, 102], suggesting that the etiology of breast cancer may differ among pre- and postmenopausal women.

There are several potential mechanisms linking MS with an increased risk of breast cancer. First, obese postmenopausal women produce higher levels of estrogens, which in turn increase the biologically available fraction of circulating estradiol by reducing plasma concentration of sex hormone binding globulin (SHBG) [103]. Low plasma SHBG levels are associated with insulin resistance $[104,105]$ and other components of MS [106, 107]. Second, adipose tissue produces two adipokines (cytokine-like factors), leptin and adiponectin, that affect breast cancer biology [108]. Higher plasma leptin levels are associated with obesity $[54,57,109]$, insulin resistance $[110,111]$, and MS $[112,113]$. Leptin stimulates human breast cancer cell lines, whereas adiponectin acts protectively, inhibiting the growth of these cell lines $[57,108,114]$. Obesity is associated with reduced adiponectin levels [115]. Third, insulin has been shown to have a mitogenic effect upon breast cancer cells in vitro through several mechanisms [57]. It can act synergistically with estradiol and stimulate proliferation of the cell line [116]. Insulin can also lower SHBG production [117], thereby increasing biologically available estradiol. Moreover, low serum HDL-C concentrations indicate higher circulating bioactive estrogen levels, which in turn may stimulate target breast tissue [77].

The increasing prevalence of MS and its association with breast cancer, among other comorbidities, point toward the critical need to develop public health strategies to manage MS. Given the increasingly large global burden of metabolic risk factors, even a small association with breast cancer can have a substantial public health impact. Risk assessment tools can be developed which incorporate MS as a risk factor for breast cancer. Healthcare providers will then be better equipped to identify high-risk women for primary and secondary prevention.

This study has several strengths. First, to the best of our knowledge, this is the first systematic review and metaanalysis examining the association between MS and risk of breast cancer in all adult women. The analysis incorporates all women and a subanalysis of postmenopausal women. The overlapping meta-analysis on metabolic syndrome and breast cancer was confined to postmenopausal women only [10]. Second, a number of other analyses were performed which strengthened the robustness of findings. Third, the results of this study provide direction for future research on this topic.

This study also has several potential limitations. These include (1) the different methods used to assess exposure, identify cancer, control for confounders, and define MS, (2) limiting studies to those published in English, which may have inflated the results [118], (3) the relatively small number of studies that met the inclusion criteria, (4) the inability of some studies to provide raw data for calculating the RR, (5) the different study designs employed, and (6) the varied populations studied, including those with diabetes and/or taking medications for diabetes. Most notably and with respect to controlling for adiposity, a potential confounder, two of the included studies controlled for BMI $[48,62]$ but no information was available from the other studies with respect to controlling for BMI or any other obesity-related measures, including such measures of central obesity as waist circumference and waist-to-hip ratio $[13,14,43,51,63,64]$. Given the potential association between breast cancer and adiposity, it may be prudent for future studies to control for this potential confounder. This may be especially true for measures of central adiposity. To this point, Kabat et al. suggested that some, but not all, studies have reported an association between increased central adiposity and an increased risk for postmenopausal breast cancer [48]. Another limitation was a lack of information on tumor subtypes. The inclusion of such information in future studies may be important, given the potential differences in risk according to exposure and disease subtype.

In order to inform and undergird a biological rationale for the observed positive association between MS and breast cancer risk in adult females, future research should comprise analyses based on a standard definition of MS and employ objective and standard biomarkers for assessing each MS component. In addition, adjustments for all important potential confounders need to be made. It would be helpful if future studies examined the relationship between MS and breast cancer risk separately in perimenopausal and premenopausal women since breast cancer in women may be estrogenindependent. Along those lines, not all studies adjusted for hormone replacement therapy, a potential confounder. Future studies should report this information. Furthermore, they need to examine in situ and invasive cancers separately in relation to metabolic syndrome. Finally, a focus on obese women with respect to MS and breast cancer seems appropriate.

In conclusion, the overall results of this meta-analysis suggest that there is a modest positive association between MS and risk of breast cancer in adult females.

\section{Disclaimer}

The findings and conclusions in this report are those of the authors and do not necessarily represent the views of the National Institute for Occupational Safety and Health.

\section{Conflict of Interests}

The authors declare that there is no conflict of interests regarding the publication of this paper.

\section{Acknowledgment}

This work was done when Ruchi Bhandari was a doctoral student at West Virginia University.

\section{References}

[1] J. Ferlay, I. Soerjomataram, M. Ervik et al., GLOBOCAN 2012 v1.0, Cancer Incidence and Mortality Worldwide: IARC 
CancerBase No. 11, International Agency for Research on Cancer, Lyon, France, 2013.

[2] National Cancer Institute. Breast Cancer-Risk Factors, http://www.cancer.gov/cancertopics/wyntk/breast/page4.

[3] S. M. Grundy, H. B. Brewer Jr., J. I. Cleeman, S. C. Smith Jr., and C. Lenfant, "Definition of metabolic syndrome: report of the National Heart, Lung, and Blood Institute/American Heart Association conference on scientific issues related to definition," Circulation, vol. 109, no. 3, pp. 433-438, 2004.

[4] G. M. Reaven, "Role of insulin resistance in human disease," Diabetes, vol. 37, no. 12, pp. 1595-1607, 1988.

[5] World Health Organization, Definition, Diagnosis and Classification of Diabetes Mellitus and Its Complications: Report of a WHO Consultation, World Health Organization, Geneva, Switzerland, 1999.

[6] "Third Report of the National Cholesterol Education Program (NCEP) Expert Panel on Detection, Evaluation, and Treatment of High Blood Cholesterol in Adults (Adult Treatment Panel III) final report," Circulation, vol. 106, no. 25, pp. 3143-3421, 2002.

[7] S. M. Grundy, J. I. Cleeman, S. R. Daniels et al., "Diagnosis and management of the metabolic syndrome: an American Heart Association/National Heart, Lung, and Blood Institute scientific statement," Circulation, vol. 112, no. 17, pp. 2735-2752, 2005.

[8] K. G. Alberti, P. Zimmet, and J. Shaw, "The metabolic syndrome-a new worldwide definition," The Lancet, vol. 366, no. 9491, pp. 1059-1062, 2005.

[9] S. M. Grundy, "Metabolic syndrome pandemic," Arteriosclerosis, Thrombosis, and Vascular Biology, vol. 28, pp. 629-636, 2008.

[10] K. Esposito, P. Chiodini, A. Capuano et al., "Metabolic syndrome and postmenopausal breast cancer: systematic review and meta-analysis," Menopause, vol. 20, no. 12, pp. 1301-1309, 2013.

[11] K. Esposito, P. Chiodini, A. Capuano et al., "Effect ofmetabolic syndrome and its components on prostate cancer risk: metaanalysis," Journal of Endocrinological Investigation, vol. 36, no. 2, pp. 132-139, 2013.

[12] K. Esposito, P. Chiodini, A. Capuano et al., "Colorectal cancer association with metabolic syndrome and its components: a systematic review with meta-analysis," Endocrine, vol. 44, no. 3, pp. 634-647, 2013.

[13] Y. Osaki, S.-I. Taniguchi, A. Tahara, M. Okamoto, and T. Kishimoto, "Metabolic syndrome and incidence of liver and breast cancers in Japan," Cancer Epidemiology, vol. 36, no. 2, pp. 141-147, 2012.

[14] V. Rosato, C. Bosetti, R. Talamini et al., "Metabolic syndrome and the risk of breast cancer in postmenopausal women," Annals of Oncology, vol. 22, no. 12, pp. 2687-2692, 2011.

[15] V. Rosato, A. Tavani, C. Bosetti et al., "Metabolic syndrome and pancreatic cancer risk: a case-control study in Italy and metaanalysis," Metabolism: Clinical and Experimental, vol. 60, no. 10, pp. 1372-1378, 2011.

[16] P. A. van den Brandt, D. Spiegelman, S.-S. Yaun et al., "Pooled analysis of prospective cohort studies on height, weight, and breast cancer risk," American Journal of Epidemiology, vol. 152, no. 6 , pp. 514-527, 2000.

[17] Z. Huang, S. E. Hankinson, G. A. Colditz et al., "Dual effects of weight and weight gain on breast cancer risk," Journal of the American Medical Association, vol. 278, no. 17, pp. 1407-1411, 1997.

[18] M. Harvie, L. Hooper, and A. H. Howell, "Central obesity and breast cancer risk: a systematic review," Obesity Reviews, vol. 4, no. 3, pp. 157-173, 2003.
[19] K. B. Michels, C. G. Solomon, F. B. Hu et al., "Type 2 diabetes and subsequent incidence of breast cancer in the nurses' health study," Diabetes Care, vol. 26, no. 6, pp. 1752-1758, 2003.

[20] F. de Waard and E. A. Baanders van Halewijn, "A prospective study in general practice on breast cancer risk in postmenopausal women," International Journal of Cancer, vol. 14, no. 2, pp. 153-160, 1974.

[21] P. J. Mink, E. Shahar, W. D. Rosamond, A. J. Alberg, and A. R. Folsom, "Serum insulin and glucose levels and breast cancer incidence: the atherosclerosis risk in communities study," The American Journal of Epidemiology, vol. 156, no. 4, pp. 349-352, 2002.

[22] S. A. Tornberg, L.-E. Holm, and J. M. Carstensen, "Breast cancer risk in relation to serum cholesterol, serum beta-lipoprotein, height, weight, and blood pressure," Acta Oncologica, vol. 27, no. 1, pp. 31-37, 1988.

[23] M. Soler, L. Chatenoud, E. Negri, F. Parazzini, S. Franceschi, and C. La Vecchia, "Hypertension and hormone-related neoplasms in women," Hypertension, vol. 34, no. 2, pp. 320-325, 1999.

[24] J. A. Largent, A. J. McEligot, A. Ziogas et al., "Hypertension, diuretics and breast cancer risk," Journal of Human Hypertension, vol. 20, no. 10, pp. 727-732, 2006.

[25] G. Llaverias, C. Danilo, I. Mercier et al., "Role of cholesterol in the development and progression of breast cancer," The American Journal of Pathology, vol. 178, no. 1, pp. 402-412, 2011.

[26] M. Gerber, F. Cavallo, E. Marubini et al., "Liposoluble vitamins and lipid parameters in breast cancer. A joint study in northern Italy and southern France," International Journal of Cancer, vol. 42, no. 4, pp. 489-494, 1988.

[27] C. G. Alexopoulos, B. Blatsios, and A. Avgerinos, "Serum lipids and lipoprotein disorders in cancer patients," Cancer, vol. 60, no. 12, pp. 3065-3070, 1987.

[28] S. C. Larsson, C. S. Mantzoros, and A. Wolk, "Diabetes mellitus and risk of breast cancer: a meta-analysis," International Journal of Cancer, vol. 121, no. 4, pp. 856-862, 2007.

[29] M. T. Goodman, J. B. Cologne, H. Moriwaki, M. Vaeth, and K. Mabuchi, "Risk factors for primary breast cancer in Japan: 8year follow-up of atomic bomb survivors," Preventive Medicine, vol. 26, no. 1, pp. 144-153, 1997.

[30] E. Weiderpass, G. Gridley, I. Persson, O. Nyren, A. Ekbom, and H. O. Adami, "Risk of endometrial and breast cancer in patients with diabetes mellitus," International Journal of Cancer, vol. 71, pp. 360-363, 1997.

[31] L. Wideroff, G. Gridley, L. Mellemkjaer et al., "Cancer incidence in a population-based cohort of patients hospitalized with diabetes mellitus in denmark," Journal of the National Cancer Institute, vol. 89, no. 18, pp. 1360-1365, 1997.

[32] S. H. Jee, H. J. Sun, H. Ohrr et al., "Fasting serum glucose level and cancer risk in Korean men and women," The Journal of the American Medical Association, vol. 293, no. 2, pp. 194-202, 2005.

[33] P. Boyle, M. Boniol, and A. Koechlin, "Diabetes and breast cancer risk: a meta-analysis," British Journal of Cancer, vol. 107, pp. 1608-1617, 2012.

[34] L. M. Morimoto, E. White, Z. Chen et al., "Obesity, body size, and risk of postmenopausal breast cancer: the women's health initiative (United States)," Cancer Causes and Control, vol. 13, no. 8, pp. 741-751, 2002.

[35] World Cancer Research Fund, Food, Nutrition, Physical Activity, and the Prevention of Cancer: A Global Perspective, American Institute for Cancer Research, Washington, DC, USA, 2nd edition, 2007. 
[36] G. Ursin, M. P. Longnecker, R. W. Haile, and S. Greenland, "A meta-analysis of body mass index and risk of premenopausal breast cancer," Epidemiology, vol. 6, no. 2, pp. 137-141, 1995.

[37] D. R. Pathak and A. S. Whittemore, "Combined effects of body size, parity, and menstrual events on breast cancer incidence in seven countries," The American Journal of Epidemiology, vol. 135, no. 2, pp. 153-168, 1992.

[38] S. L. Peacock, E. White, J. R. Daling, L. F. Voigt, and K. E. Malone, "Relation between obesity and breast cancer in young women," American Journal of Epidemiology, vol. 149, no. 4, pp. 339-346, 1999.

[39] J. Manjer, R. Kaaks, E. Riboli, and G. Berglund, "Risk of breast cancer in relation to anthropometry, blood pressure, blood lipids and glucose metabolism: a prospective study within the Malmö Preventive Project," European Journal of Cancer Prevention, vol. 10, no. 1, pp. 33-42, 2001.

[40] P. H. M. Peeters, P. A. H. van Noord, A. W. Hoes, J. Fracheboud, C. H. F. Gimbrère, and D. E. Grobbee, "Hypertension and breast cancer risk in a 19-year follow-up study (the DOM cohort)," Journal of Hypertension, vol. 18, no. 3, pp. 249-254, 2000.

[41] T. Agurs-Collins, K. S. Kim, G. M. Dunston, and L. L. AdamsCampbell, "Plasma lipid alterations in African-American women with breast cancer," Journal of Cancer Research and Clinical Oncology, vol. 124, no. 3-4, pp. 186-190, 1998.

[42] M. Ha, J. Sung, and Y.-M. Song, "Serum total cholesterol and the risk of breast cancer in postmenopausal Korean women," Cancer Causes and Control, vol. 20, no. 7, pp. 1055-1060, 2009.

[43] C. Agnoli, F. Berrino, C. A. Abagnato et al., "Metabolic syndrome and postmenopausal breast cancer in the ORDET cohort: a nested case-control study," Nutrition, Metabolism and Cardiovascular Diseases, vol. 20, no. 1, pp. 41-48, 2010.

[44] L. M. Beaulieu, B. R. Whitley, T. F. Wiesner et al., "Breast cancer and metabolic syndrome linked through the plasminogen activator inhibitor-1 cycle," BioEssays, vol. 29, no. 10, pp. 10291038, 2007.

[45] T. Bjørge, A. Lukanova, H. Jonsson et al., "Metabolic syndrome and breast cancer in the Me-Can (metabolic syndrome and cancer) project," Cancer Epidemiology Biomarkers and Prevention, vol. 19, no. 7, pp. 1737-1745, 2010.

[46] I. Capasso, E. Esposito, F. Pentimalli et al., "Metabolic syndrome affects breast-cancer risk in postmenopausal women: National Cancer Institute of Naples experience," Cancer Biology and Therapy, vol. 10, no. 12, pp. 1240-1243, 2010.

[47] L. A. Healy, A. M. Ryan, P. Carroll et al., "Metabolic syndrome, central obesity and insulin resistance are associated with adverse pathological features in postmenopausal breast cancer," Clinical Oncology, vol. 22, no. 4, pp. 281-288, 2010.

[48] G. C. Kabat, M. Kim, R. T. Chlebowski et al., "A longitudinal study of the metabolic syndrome and risk of postmenopausal breast cancer," Cancer Epidemiology, Biomarkers \& Prevention, vol. 18, no. 7, pp. 2046-2053, 2009.

[49] B. Maiti, M. N. Kundranda, T. P. Spiro, and H. A. Daw, "The association of metabolic syndrome with triple-negative breast cancer," Breast Cancer Research and Treatment, vol. 121, no. 2, pp. 479-483, 2010.

[50] L. A. M. Porto, K. J. B. Lora, J. C. M. Soares, and L. O. B. F. Costa, "Metabolic syndrome is an independent risk factor for breast cancer," Archives of Gynecology and Obstetrics, vol. 284, no. 5, pp. 1271-1276, 2011.

[51] A. L. Ronco, E. De Stéfani, H. Deneo-Pellegrini, and A. Quarneti, "Diabetes, overweight and risk of postmenopausal breast cancer: a case-control study in Uruguay," Asian Pacific Journal of Cancer Prevention, vol. 13, no. 1, pp. 139-146, 2012.

[52] D. P. Rose, S. M. Haffner, and J. Baillargeon, "Adiposity, the metabolic syndrome, and breast cancer in African-American and white American women," Endocrine Reviews, vol. 28, no. 7, pp. 763-777, 2007.

[53] D. Sinagra, C. Amato, A. M. Scarpilta et al., "Metabolic syndrome and breast cancer risk," European Review for Medical and Pharmacological Sciences, vol. 6, pp. 55-59, 2002.

[54] L. Vona-Davis, M. Howard-Mcnatt, and D. P. Rose, "Adiposity, type 2 diabetes and the metabolic syndrome in breast cancer," Obesity Reviews, vol. 8, no. 5, pp. 395-408, 2007.

[55] F. Xue and K. B. Michels, "Diabetes, metabolic syndrome, and breast cancer: a review of the current evidence," The American Journal of Clinical Nutrition, vol. 86, no. 3, pp. s823-s835, 2007.

[56] K. Esposito, P. Chiodini, A. Colao, A. Lenzi, and D. Giugliano, "Metabolic syndrome and risk of cancer: a systematic review and meta-analysis," Diabetes Care, vol. 35, no. 11, pp. 2402-2411, 2012.

[57] D. P. Rose, D. Komninou, and G. D. Stephenson, "Obesity, adipocytokines, and insulin resistance in breast cancer," Obesity Reviews, vol. 5, no. 3, pp. 153-165, 2004.

[58] S. Liao, J. Li, W. Wei et al., "Association between diabetes mellitus and breast cancer risk: a meta-analysis of the literature," Asian Pacific Journal of Cancer Prevention, vol. 12, no. 4, pp. 1061-1065, 2011.

[59] E. Giovannucci, D. M. Harlan, M. C. Archer et al., "Diabetes and cancer: a consensus report," Diabetes Care, vol. 33, no. 7, pp. 1674-1685, 2010.

[60] T. Jarde, S. Perrier, M. P. Vasson, and F. Caldefie-Chezet, "Molecular mechanisms of leptin and adiponectin in breast cancer," European Journal of Cancer, vol. 47, no. 1, pp. 33-43, 2011.

[61] J. E. Goldberg and K. L. Schwertfeger, "Proinflammatory cytokines in breast cancer: mechanisms of action and potential targets for therapeutics," Current Drug Targets, vol. 11, no. 9, pp. 1133-1146, 2010.

[62] J. L. F. Bosco, "Selected medications, cardiometabolic risk factors, and breast cancer risk," Proquest Dissertations \& Theses UMI 3445685, 2011.

[63] M. Inoue, M. Noda, N. Kurahashi et al., "Impact of metabolic factors on subsequent cancer risk: results from a large-scale population-based cohort study in Japan," European Journal of Cancer Prevention, vol. 18, no. 3, pp. 240-247, 2009.

[64] A. Russo, M. Autelitano, and L. Bisanti, "Metabolic syndrome and cancer risk," European Journal of Cancer, vol. 44, no. 2, pp. 293-297, 2008.

[65] G. Glass, B. McGaw, and M. L. Smith, Meta-Analysis in Social Research, Sage, 1981.

[66] J. Cohen, "Weighted kappa: nominal scale agreement provision for scaled disagreement or partial credit," Psychological Bulletin, vol. 70, no. 4, pp. 213-220, 1968.

[67] J. P. Vandenbroucke, E. Von Elm, D. G. Altman et al., "Strengthening the reporting of observational studies in epidemiology (STROBE): explanation and elaboration," Gaceta Sanitaria, vol. 23, no. 2, pp. 158.e1-158.e28, 2009.

[68] R. DerSimonian and N. Laird, "Meta-analysis in clinical trials," Controlled Clinical Trials, vol. 7, no. 3, pp. 177-188, 1986.

[69] W. G. Cochran, "Research techniques in the study of human beings," The Milbank Memorial Fund Quarterly, vol. 33, no. 2, pp. 121-136, 1955. 
[70] J. P. T. Higgins and S. G. Thompson, "Quantifying heterogeneity in a meta-analysis," Statistics in Medicine, vol. 21, no. 11, pp. 15391558, 2002.

[71] S. Duval and R. Tweedie, “Trim and fill: a simple funnel-plotbased method of testing and adjusting for publication bias in meta-analysis," Biometrics, vol. 56, no. 2, pp. 455-463, 2000.

[72] R. Rosenthal, "The file drawer problem and tolerance for null results," Psychological Bulletin, vol. 86, no. 3, pp. 638-641, 1979.

[73] M. Borenstein, L. Hedges, J. Higgins, and H. Rothstein, Comprehensive Meta Analysis Version 2, Biostat, Englewood, NJ, USA, 2005.

[74] J. Brunet, A. Vazquez-Martin, R. Colomer, B. Graña-Suarez, B. Martin-Castillo, and J. A. Menendez, "BRCA1 and acetylCoA carboxylase: the metabolic syndrome of breast cancer," Molecular Carcinogenesis, vol. 47, no. 2, pp. 157-163, 2008.

[75] E. Bugianesi, "Review article: steatosis, the metabolic syndrome and cancer," Alimentary Pharmacology \& Therapeutics, vol. 22, supplement 2, pp. 40-43, 2005.

[76] S. M. Conroy, L. M. Butler, D. Harvey et al., "Metabolic syndrome and mammographic density: the Study of Women's Health Across the Nation," International Journal of Cancer, vol. 129, no. 7, pp. 1699-1707, 2011.

[77] A.-S. Furberg, M. B. Veierød, T. Wilsgaard, L. Berstein, and I. Thune, "Serum high density lipoprotein cholesterol, metabolic profile, and breast cancer risk," Journal of the National Cancer Institute, vol. 96, no. 15, pp. 1152-1160, 2004.

[78] A.-S. Furberg, G. Jasienska, N. Bjurstam et al., "Metabolic and hormonal profiles: HDL cholesterol as a plausible biomarker of breast cancer risk. The Norwegian EBBA study," Cancer Epidemiology, Biomarkers \& Prevention, vol. 14, no. 1, pp. 33-40, 2005.

[79] H. Kuhl, "Breast cancer risk in the WHI study: the problem of obesity," Maturitas, vol. 51, no. 1, pp. 83-97, 2005.

[80] S. W. Oh, C. Y. Park, E. S. Lee et al., "Adipokines, insulin resistance, metabolic syndrome, and breast cancer recurrence: a cohort study," Breast Cancer Research, vol. 13, no. 2, article R34, 2011.

[81] M. N. Okobia, C. H. Bunker, J. M. Zmuda et al., "Anthropometry and breast cancer risk in Nigerian women," Breast Journal, vol. 12, no. 5, pp. 462-466, 2006.

[82] P. J. Wysocki and B. Wierusz-Wysocka, "Obesity, hyperinsulinemia and breast cancer: novel targets and a novel role for metformin," Expert Review of Molecular Diagnostics, vol. 10, no. 4, pp. 509-519, 2010.

[83] C. Y. Yang, C. Y. Peng, Y. C. Liu, W. Z. Chen, and W. K. Chiou, "Surface anthropometric indices in obesity-related metabolic diseases and cancers," Chang Gung Medical Journal, vol. 34, no. 1, pp. 1-22, 2011.

[84] A. G. Antoniadis, E. T. Petridou, C. N. Antonopoulos et al., "Insulin resistance in relation to melanoma risk," Melanoma Research, vol. 21, no. 6, pp. 541-546, 2011.

[85] J. Arends, "Metabolism in cancer patients," Anticancer Research, vol. 30, no. 5, pp. 1863-1868, 2010.

[86] P. A. Carroll, L. Healy, J. Lysaght et al., "Influence of the metabolic syndrome on leptin and leptin receptor in breast cancer," Molecular Carcinogenesis, vol. 50, no. 8, pp. 643-651, 2011.

[87] S. L. Doyle, C. L. Donohoe, J. Lysaght, and J. V. Reynolds, "Visceral obesity, metabolic syndrome, insulin resistance and cancer," Proceedings of the Nutrition Society, vol. 71, no. 1, pp. 181-189, 2012.
[88] M. M. Gaudet, R. T. Falk, G. L. Gierach et al., "Do adipokines underlie the association between known risk factors and breast cancer among a cohort of United States women?" Cancer Epidemiology, vol. 34, no. 5, pp. 580-586, 2010.

[89] H. R. Harris, W. C. Willett, K. L. Terry, and K. B. Michels, "Body fat distribution and risk of premenopausal breast cancer in the nurses' health study II," Journal of the National Cancer Institute, vol. 103, no. 3, pp. 273-278, 2011.

[90] C. Heidemann, H. Boeing, T. Pischon, U. Nöthlings, H.-G. Joost, and M. B. Schulze, "Association of a diabetes risk score with risk of myocardial infarction, stroke, specific types of cancer, and mortality: a prospective study in the European Prospective Investigation into Cancer and Nutrition (EPIC)Potsdam cohort," European Journal of Epidemiology, vol. 24, no. 6, pp. 281-288, 2009.

[91] L.-N. Liu, C. Miaskowski, J.-S. Wang, S.-C. Chen, and M.-L. Chen, "Accuracy of body mass index to determine obesity in women with breast cancer: an observational study of Taiwanese sample," International Journal of Nursing Studies, vol. 47, no. 8, pp. 994-1000, 2010.

[92] K. K. Ness, J. M. Oakes, J. A. Punyko, K. S. Baker, and J. G. Gurney, "Prevalence of the metabolic syndrome in relation to self-reported cancer history," Annals of Epidemiology, vol. 15, no. 3, pp. 202-206, 2005.

[93] S. Papaioannou and J. Tzafettas, "Anovulation with or without PCO, hyperandrogenaemia and hyperinsulinaemia as promoters of endometrial and breast cancer," Best Practice \& Research: Clinical Obstetrics \& Gynaecology, vol. 24, no. 1, pp. 19-27, 2010.

[94] P. Pasanisi, F. Berrino, M. De Petris, E. Venturelli, A. Mastroianni, and S. Panico, "Metabolic syndrome as a prognostic factor for breast cancer recurrences," International Journal of Cancer, vol. 119, no. 1, pp. 236-238, 2006.

[95] S. Rinaldi, T. J. Key, P. H. M. Peeters et al., "Anthropometric measures, endogenous sex steroids and breast cancer risk in postmenopausal women: a study within the EPIC cohort," International Journal of Cancer, vol. 118, no. 11, pp. 2832-2839, 2006.

[96] B. A. Stoll, "Timing of weight gain in relation to breast cancer risk," Annals of Oncology, vol. 6, no. 3, pp. 245-248, 1995.

[97] M. Pollak, "Insulin, insulin-like growth factors and neoplasia," Best Practice and Research: Clinical Endocrinology and Metabolism, vol. 22, no. 4, pp. 625-638, 2008.

[98] E. T. Chesney, S. C. Davis, L. Duggan, and S. Natarajan, "Does metabolic syndrome increase risk for certain cancers?" American Journal for Nurse Practitioners, vol. 14, pp. 25-32, 2010.

[99] R. L. Ahmed-Saucedo, "Preview Epidemiological associations of metabolic factors with cancer risk and cancer late effects," Proquest Dissertations \& Theses UMI 3200570, 2006.

[100] S. M. Conroy, Physical activity, metabolic syndrome and insulin resistance in relation to mammographic density [ProQuest Dissertations \& Thesis], 2009, UMI 3379558.

[101] G. Ibarra-Mejia, "Exogenous environmental factors and susceptibility for breast cancer in Mexican American women," ProQuest Dissertations \& Theses UMI 3196421, 2005.

[102] C. Pichard, G. Plu-Bureau, M. Neves-e Castro, and A. Gompel, "Insulin resistance, obesity and breast cancer risk," Maturitas, vol. 60, no. 1, pp. 19-30, 2008.

[103] G. D. Stephenson and D. P. Rose, "Breast cancer and obesity: an update," Nutrition and Cancer, vol. 45, no. 1, pp. 1-16, 2003.

[104] D. Goodman-Gruen and E. Barrett-Connor, "Sex hormonebinding globulin and glucose tolerance in postmenopausal 
women: the Rancho Bernardo study," Diabetes Care, vol. 20, no. 4, pp. 645-649, 1997.

[105] K. Sherif, H. Kushner, and B. E. Falkner, "Sex hormone-binding globulin and insulin resistance in African-American women," Metabolism, vol. 47, no. 1, pp. 70-74, 1998.

[106] A. S. Cikim, N. Ozbey, E. Sencer, S. Molvalilar, and Y. Orhan, "Associations among sex hormone binding globulin concentrations and characteristics of the metabolic syndrome in obese women," Diabetes, Nutrition and Metabolism-Clinical and Experimental, vol. 17, no. 5, pp. 290-295, 2004.

[107] S. Hajamor, J.-P. Després, C. Couillard et al., "Relationship between sex hormone-binding globulin levels and features of the metabolic syndrome," Metabolism-Clinical and Experimental, vol. 52, no. 6, pp. 724-730, 2003.

[108] L. Vona-Davis and D. P. Rose, "Adipokines as endocrine, paracrine, and autocrine factors in breast cancer risk and progression," Endocrine-Related Cancer, vol. 14, no. 2, pp. 189206, 2007.

[109] S. Klein, S. W. Coppack, V. Mohamed-Ali, and M. Landt, "Adipose tissue leptin production and plasma leptin kinetics in humans," Diabetes, vol. 45, no. 3, pp. 984-987, 1996.

[110] S. Fischer, M. Hanefeld, S. M. Haffner et al., "Insulin-resistant patients with type 2 diabetes mellitus have higher serum leptin levels independently of body fat mass," Acta Diabetologica, vol. 39, no. 3, pp. 105-110, 2002.

[111] M. Wauters, R. V. Considine, J. S. Yudkin, F. Peiffer, I. de Leeuw, and L. F. van Gaal, "Leptin levels in type 2 diabetes: associations with measures of insulin resistance and insulin secretion," Hormone and Metabolic Research, vol. 35, no. 2, pp. 92-96, 2003.

[112] P. W. Franks, S. Brage, J. Luan et al., "Leptin predicts a worsening of the features of the metabolic syndrome independently of obesity," Obesity Research, vol. 13, no. 8, pp. 1476-1484, 2005.

[113] M. C. Chu, P. Cosper, F. Orio, E. Carmina, and R. A. Lobo, "Insulin resistance in postmenopausal women with metabolic syndrome and the measurements of adiponectin, leptin, resistin, and ghrelin," The American Journal of Obstetrics and Gynecology, vol. 194, no. 1, pp. 100-104, 2006.

[114] P. Somasundar, D. W. McFadden, S. M. Hileman, and L. VonaDavis, "Leptin is a growth factor in cancer," Journal of Surgical Research, vol. 116, no. 2, pp. 337-349, 2004.

[115] M. P. Scheid and G. Sweeney, "The role of adiponectin signaling in metabolic syndrome and cancer," Reviews in Endocrine and Metabolic Disorders, vol. 15, no. 2, pp. 157-167, 2014.

[116] M. L. Panno, M. Salerno, V. Pezzi et al., "Effect of oestradiol and insulin on the proliferative pattern and on oestrogen and progesterone receptor contents in MCF-7 cells," Journal of Cancer Research and Clinical Oncology, vol. 122, no. 12, pp. 745749, 1996.

[117] S. R. Plymate, L. A. Matej, R. E. Jones, and K. E. Friedl, "Inhibition of sex hormone-binding globulin production in the human hepatoma (Hep G2) cell line by insulin and prolactin," The Journal of Clinical Endocrinology \& Metabolism, vol. 67, no. 3, pp. 460-464, 1988.

[118] G. Gregoire, F. Derderian, and J. Le Lorier, "Selecting the language of the publications included in a meta-analysis: is there a Tower of Babel bias?" Journal of Clinical Epidemiology, vol. 48, no. 1, pp. 159-163, 1995. 


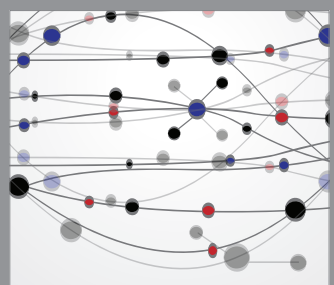

The Scientific World Journal
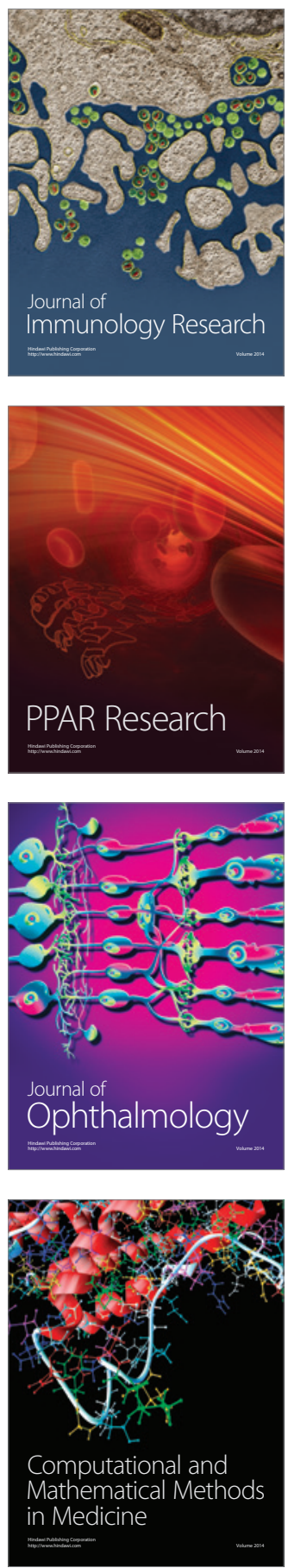

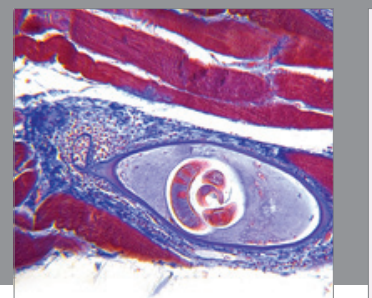

Gastroenterology

Research and Practice
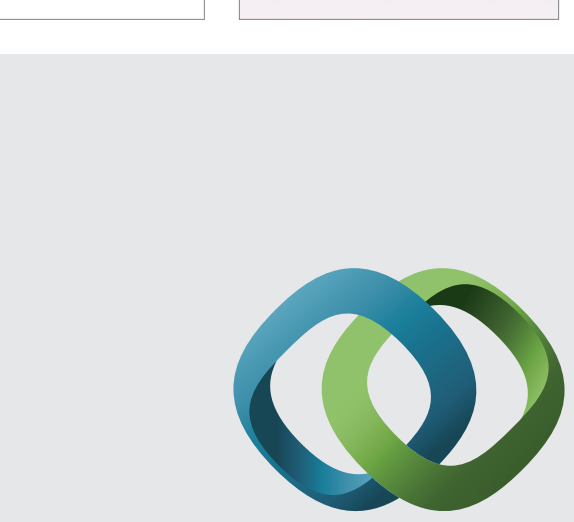

\section{Hindawi}

Submit your manuscripts at

http://www.hindawi.com
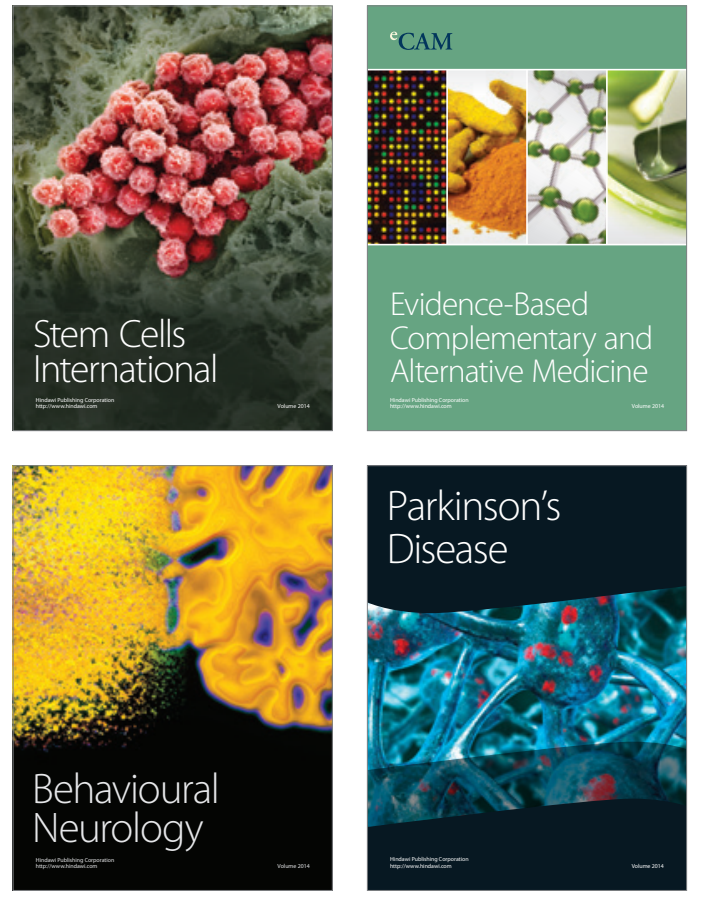
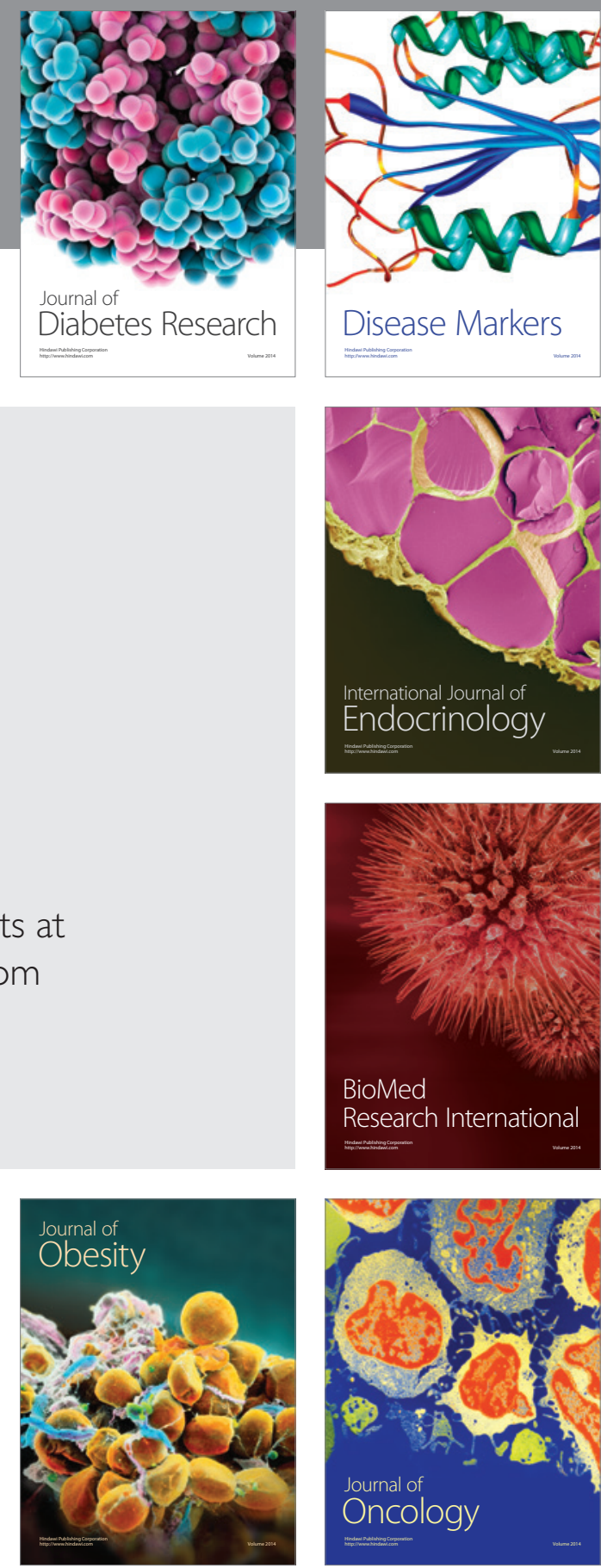

Disease Markers
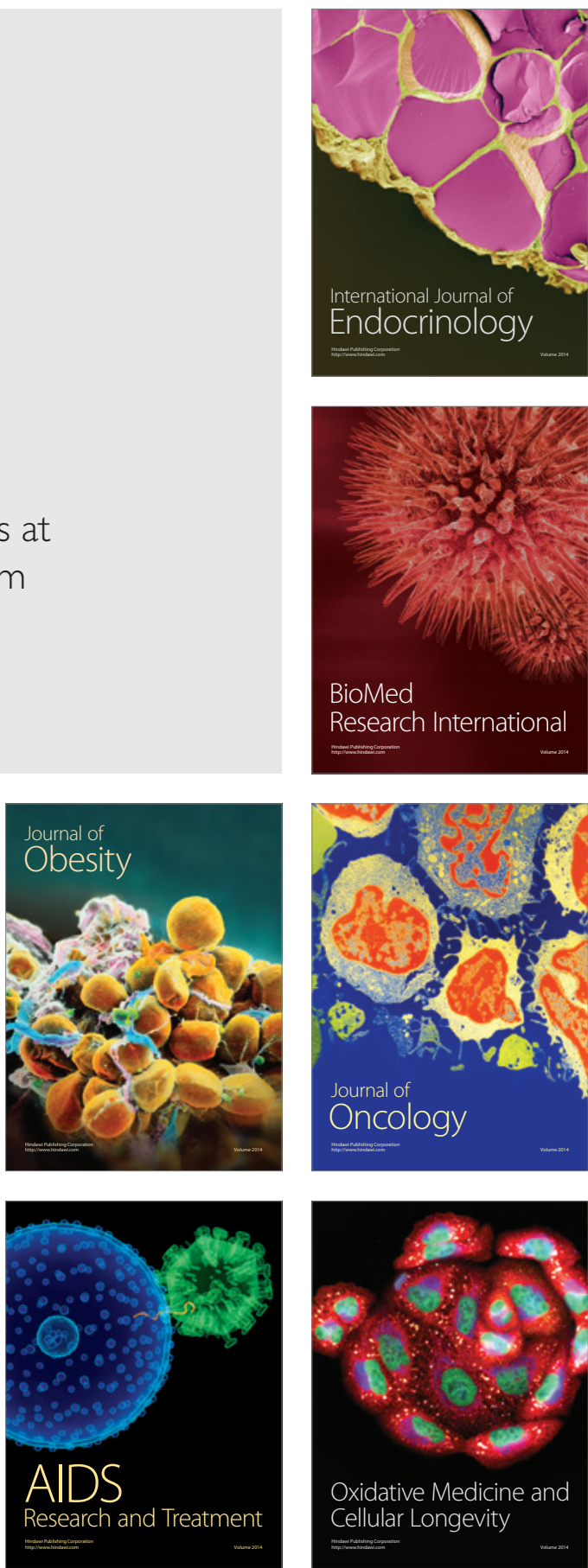